\title{
The reach and impact of Child Support Grants: evidence from KwaZulu-Natal
}

\author{
Anne Case, Victoria Hosegood \& Frances Lund ${ }^{1}$
}

This paper examines the reach and impact of the South African Child Support Grant, using longitudinal data collected through the Africa Centre for Health and Population Studies. The grant is being taken up for a third of all age-eligible resident children, and appears to be reaching those children living in the poorer households of the demographic surveillance area (DSA). Children who received the grant are significantly more likely to be enrolled in school in the years following grant receipt than are equally poor children of the same age. However, older brothers and sisters of grant recipients, when they were observed at younger ages, were less likely than other children to be enrolled in school - perhaps reflecting the greater poverty in grant-receiving households. Thus the grant appears to help overcome the impact of poverty on school enrolment.

\section{INTRODUCTION}

Poverty is again at the centre of debates about development. Dominant international institutions have committed themselves to addressing poverty, notably the World Bank, through its Poverty Reduction Strategies, and the United Nations, through the Millennium Development Goals. Discussion has also focused on alternative roles for the state, with particular interest in the part the state may play in social protection, and in addressing chronic poverty.

Government intervention can take many forms, one of which is the direct provision of cash. While cash transfers have long been a standard part of the welfare systems of advanced industrial countries, they have been less commonly found in lower and middle income countries.

Cash pensions provided to the elderly in South Africa and Namibia have been found to have marked redistributive and developmental effects (Ardington \& Lund, 1995; Case \& Deaton, 1998; Devereux, 2001). Perhaps better known are the conditional cash transfer programmes to families with children in Latin America, Oportunidades (formerly PROGRESA) in Mexico and Bolsa Escola in Brazil. Both of these programmes allocate monthly transfers to poor families with children, conditional on household healthrelated behaviours. The Mexican programme has shown promising results, measured against the yardsticks of child anthropometrics and childhood morbidity (Gertler \&

\footnotetext{
${ }^{1}$ Respectively Professor of Economics and Public Affairs, Princeton University; Research Fellow, Centre for Population Studies, London School of Hygiene and Tropical Medicine and Africa Centre for Health and Populations Studies; and Associate Professor, School of Development Studies, University of KwaZulu-Natal. The authors are affiliated to the Population Studies Group of the Africa Centre for Health and Population Studies. Analysis is based on data collected through the Africa Centre Demographic Information System (ACDIS). We have benefited from the help of the ACDIS field and data centre staff under the leadership of the principal investigator, Dr Kobus Herbst. We thank Anna-Maria Vanneste for assisting with the development of the child grant questionnaire, and Shirin Motala, Lawrence Haddad, and seminar participants at the School of Development Studies, University of Natal, and Princeton University for helpful comments. This work was supported by Wellcome Trust Grants to the Africa Centre for Health and Population Studies. Case acknowledges funding from the National Institutes of Health and the MacArthur Foundation. Hosegood acknowledges funding from The Wellcome Trust, UK through grants to the Africa Centre and V Hosegood.
} 
Boyce, 2001). For policy purposes, understanding whether the success is due to nutritional supplements, prenatal or antenatal clinic visits, children's wellness visits to clinics, or the cash itself, is an important next step.

In this paper, the authors examine the success of the Child Support Grant a nonconditional means-tested cash transfer targeted at poor children under the age of 7 in South Africa. By early 2002, if a child's parents' or primary caregiver's total income did not exceed R1100 per month (\$470 per month in purchasing power parity dollars), the primary caregiver could receive a monthly amount of R110 per eligible child. The programme has since been extended from children younger than 7 to children younger than 14. Monthly payments have periodically been increased and in 2005 stand at R180 per month. (A detailed description of the programme is presented in Lund, 2002a.)

The grant's performance has high salience, within South Africa and internationally. When selected as South Africa's policy for addressing child poverty in the mid-1990s, the Child Support Grant was unusual in introducing a cash, rather than in-kind, benefit that was non-conditional. In addition, the programme was unique in providing access to the grant through a primary caregiver, in contrast to a biological parent, in order to reflect the varied and fluid patterns of care giving observed in South Africa.

The authors assessed the reach and early impact of the Child Support Grant in the Umkhanyakude District of KwaZulu-Natal. The District is poor and mostly rural. In 2001, 8 per cent of households had piped water inside their dwellings (Case \& Ardington, 2004a) - in contrast to 30 per cent for KZN, and 32 per cent for the country as a whole (Statistics South Africa, Census 2001). Thirty-nine per cent of households had no toilet facilities on site. Only 50 per cent of households were connected to an electricity grid. The District is bearing a heavy disease and death burden, associated with the HIV/ AIDS crisis (Hosegood et al., 2004). Umkhanyakude is thus precisely the kind of area that the Child Support Grant is intended to reach.

The authors examined the reach and impact of this non-conditional cash transfer using data collected through the Africa Centre for Health and Population Studies, which runs a longitudinal demographic surveillance system (DSS) in the District (see Hosegood \& Timæus, 2001 for details). In 2002, the Africa Centre added a module to its core set of questions, in which it asked a battery of questions about grants for each child in the approximately 11000 African households in the demographic surveillance area (DSA). These data made it possible to evaluate the reach of this grant. It was found that the grant is being taken up for a third of all age-eligible resident children in the DSA and that, based on parents' characteristics and household assets, the grant appears to be reaching those children living in the DSA's poorer households.

Importantly, because the data are part of a comprehensive longitudinal data collection effort for this DSA, it was also possible to relate grant receipt to children's outcomes. In particular, data on children's school enrolment in the years after the grant was received was used to assess whether the grant appears to affect children's schooling. It was found that children who received the grant are significantly more likely to be enrolled in school in the years following grant receipt than are equally poor children of the same age.

To evaluate whether the Child Support Grant plays a causal role in helping children get to school, outcomes across maternal siblings were compared. Older children in the field site would never have been eligible for the grant, because it was not yet on the ground in KwaZulu-Natal when these (now older) children were themselves aged 6 or younger. 
Older siblings thus offered a counterfactual for what would have been true for younger siblings, if the Child Support Grant had not been introduced. The longitudinal data made it possible to look back to the time when older siblings were themselves reaching school age. It was found that older siblings of current grant recipients were significantly less likely to be enrolled in school than other children of the same age when these older siblings were 7 and 8 years old - perhaps a reflection of their poverty. That their younger siblings (the children with a Child Support Grant who were observed) are more likely to be enrolled suggests that the grant may help to overcome the impact of poverty on school enrolment.

\section{CHILD SUPPORT GRANTS IN THE DSA}

Data collected by the Africa Centre in 2002 contained the question: 'Since 1998, has any adult member of this household received, is in the process of applying for, or been refused a grant for a child?' Households were also asked 'Since 1998, is there any child member of this household for whom an adult who is not a member of this household has applied for, received, or been refused a grant?' For households that answered either question affirmatively, details were collected on the adult grant holder, the child's identity, the relationship of the child to the adult, and the type of grant. In addition, information was collected on the status of the grant at the time of the interview: Had the adult made a first visit, submitted an application, been awarded a grant, received a grant, or had an application denied? In all that follows, the phrase 'grant reported' is used to mean that the household informant reported that the child's caregiver was at any stage in the process (first visit; submitted an application; received or denied a grant). The phrase 'grant received' refers to an award having been received.

A total of 11178 households answered the grant questionnaire. Of these, 3615 households reported 6039 grants, with the overwhelming majority (94 per cent) reporting Child Support Grants. In this section, we focus exclusively on the 12865 children under the age of 7 who were resident in the DSA on 1 January 2002, of whom 4684 had a Child Support Grant reported on their behalf. Of these children, 3754 were actively receiving a Child Support Grant. The Appendix provides details of the sample used here.

Information on the children under the age of 7 in the DSA is reported in Table 1, where sample means are presented separately for children for whom a Child Support Grant is not reported (column 1), and those for whom a grant is reported (column 2). For each variable, an asterisk $\left(^{*}\right)$ indicates when the difference in sample means is statistically significant. Children for whom a grant is reported are slightly, but significantly, older on average. Their mothers and fathers are on average one year older than are those of children for whom a grant is not reported. Indeed, only 3.7 per cent of children in the Child Support Grant system have teenaged mothers, in contrast to 8.7 per cent of children not in the system. This 5 percentage point differential is mirrored in the difference in the fraction of children who were born to teenaged mothers (12 per cent of children in the grant system, in contrast to 17 per cent of children not in the system). This stands in stark contrast to the popular notion that teenage girls are becoming pregnant in order to access the Child Support Grant. If this were the reason young women were becoming pregnant, we should expect to see teenaged mothers at least as likely to apply for grants. This is not what we find in the DSA: disproportionately, it is older mothers who apply for grants.

Children for whom a grant is reported are also significantly more likely to be co-resident with their mothers. This difference is quite large: 82 per cent of children for whom a 
Table 1: Mean characteristics of children below age 7 in the DSA ${ }^{\mathrm{a}}$

\begin{tabular}{|c|c|c|}
\hline & $\begin{array}{c}\text { Children for whom a } \\
\text { Child Support Grant is } \\
\text { not reported }\end{array}$ & $\begin{array}{c}\text { Children for whom a } \\
\text { Child Support Grant is } \\
\text { reported }\end{array}$ \\
\hline Age & 3.08 & $3.18^{*}$ \\
\hline Proportion female & 0.50 & 0.50 \\
\hline Mother's age & $\begin{array}{c}29.3 \\
{[n=6856]}\end{array}$ & $\begin{array}{c}31.0^{*} \\
{[\mathrm{n}=4356]}\end{array}$ \\
\hline Mother is less than 20 years old & 0.087 & $.037^{*}$ \\
\hline Mother was less than age 20 at the child's birth & 0.17 & $0.12^{*}$ \\
\hline Father's age & $\begin{array}{c}38.3 \\
{[\mathrm{n}=3058]}\end{array}$ & $\begin{array}{c}41.4^{*} \\
{[\mathrm{n}=1942]}\end{array}$ \\
\hline $\begin{array}{l}\text { Mother and child are both resident members of } \\
\text { the same bounded structure }{ }^{b}\end{array}$ & 0.67 & $0.82^{*}$ \\
\hline $\begin{array}{l}\text { Mother is a non-resident member of child's } \\
\text { bounded structure }\end{array}$ & 0.14 & $0.10^{*}$ \\
\hline Mother is dead & 0.04 & $0.02^{*}$ \\
\hline $\begin{array}{l}\text { Mother is neither a resident nor non-resident } \\
\text { member, nor is mother known to be dead }\end{array}$ & 0.16 & $0.06^{*}$ \\
\hline $\begin{array}{l}\text { Father and child are both resident members of } \\
\text { the same bounded structure }\end{array}$ & 0.20 & $0.24^{*}$ \\
\hline $\begin{array}{l}\text { Father is a non-resident member of child's } \\
\text { bounded structure }\end{array}$ & 0.16 & 0.16 \\
\hline Father is dead & 0.04 & $0.07^{*}$ \\
\hline $\begin{array}{c}\text { Father is neither a resident nor a non-resident } \\
\text { member, nor is father known to be dead }\end{array}$ & 0.60 & $0.52^{*}$ \\
\hline $\begin{array}{l}\text { Mother, father and child are all resident } \\
\text { members of the same bounded structure }\end{array}$ & 0.16 & $0.22^{*}$ \\
\hline Number of assets owned by household & $\begin{array}{c}7.85 \\
{[n=7400]}\end{array}$ & $\begin{array}{c}7.59^{*} \\
{[n=4352]}\end{array}$ \\
\hline Number of observations $^{c}$ & 8181 & 4684 \\
\hline
\end{tabular}

${ }^{\text {a }}$ Sample is restricted to those children resident in the DSA on 1 January 2002 for whom a household identifier is known. See Appendix for details. Asterisks $\left(^{*}\right)$ denote that the difference in means between the two samples is significant at the 1 per cent level.

${ }^{\mathrm{b}} \mathrm{A}$ bounded structure is a physical area (compound, house) that has a single owner.

'Numbers of observations are given at the bottom of each column, with the exception of mother's and father's ages, and number of assets owned by the child's household - variables for which there are missing values. Numbers of observations in these cases are given in square brackets.

grant is reported are co-resident with their mothers, in contrast to only 67 per cent of children without a grant.

Children with a grant reported are almost twice as likely to be paternal orphans (7 per cent versus 4 per cent). For the majority of children, the father's status was unknown at the time of the survey. These are fathers who are neither resident nor non-resident members of households in which their children are members, and who are not known to be dead. 
Largely as a consequence of parents being missing, parents' ages are not recorded for a high percentage of children. In the results presented in Tables 2-4, when we control for mother's or father's age we do so by including a complete set of indicator variables for parents' ages. Included is an indicator variable for the parent's age being missing.

Girls appear to be at no disadvantage for a Child Support Grant. In this and the analysis that follows, an indicator that the child is a girl is never a significant predictor of a grant report. This is consistent with the lack of bias against girls found in other areas, such as school enrolment (South African Government, 1996).

Twenty per cent of children under 1 year of have had at least an inquiry made on their behalf. This rises to 40 per cent for children between the ages of 1 and 5, and falls to 30 per cent for children aged 6. Caregivers of the youngest children may not yet have learned how to apply for a grant; those of the oldest children may have decided that there were not sufficient months of support left before the child turned 7 (and became ineligible) to justify the effort associated with obtaining a grant.

More than 80 per cent of all of the children above the age of 1 year for whom an inquiry has been made are currently receiving a Child Support Grant. This can be seen in Figure 1, which presents progress through the system, by age. For children under 1 for whom contact has been made with the Child Support Grant system, 50 per cent have either made a first visit or submitted an application. The first two panels of Figure 1 show that children aged 6 months to 1 year are more likely to be receiving an award (50.4 per cent) than those aged 0 to 6 months (18.8 per cent). A full 86 per

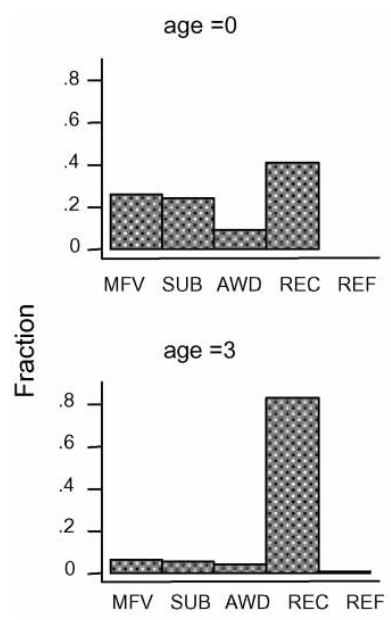

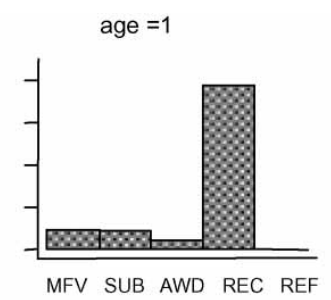

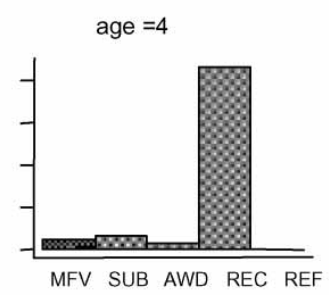

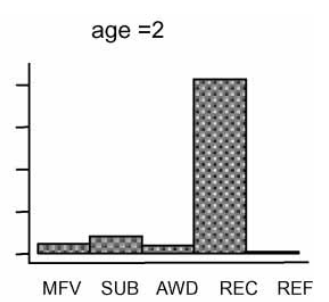

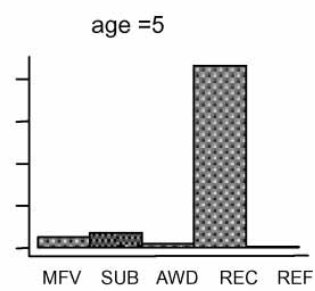

Figure 1: Child Support Grant status, by age, for resident children aged 0 to 5. Notes: For those children reported to have had contact with the Child Support Grant system, the graphs above present the stage to which the application process had advanced by 2002. Shown separately by age are: MFV: the fraction for whom only a first visit has been made (6.8\% over all children $<$ age 7$)$; SUB: an application has been submitted (7.8\%); AWD: an award has been made, but not yet received $(3.6 \%)$; REC: the grant has been received $(80.2 \%)$; REF: the application was refused $(0.3 \%)$. Results for 6 year olds (not shown) look very similar to those for 5 year olds. Not shown are a small number of children for whom it is reported that the grant has been stopped 
cent of 4, 5 and 6 year olds for whom contact has been made are actively receiving a grant. Applications were refused for only 16 children $(0.3$ per cent) for whom an inquiry was made.

The most dramatic rise in Child Support Grant receipt occurred between 1999 and 2001. This can be seen in Figure 2, which presents the fraction of children at ages 4, 5 and 6 for whom grant receipt is reported for each year from 1998 to 2002, based on the households' reports of the date the grant was first received on behalf of each child. (Results for children aged 0 to 3 are quite similar.) The percentage of children at each age in the child grant system appears to plateau at about 40 per cent after 2001.

The above patterns show that children for whom inquiries were made have later received a Child Support Grant. In addition, we find no evidence of potential caregivers being thwarted by the system once an inquiry has been made. Of the 2971 cases for which households could recall dates of first visit and grant receipt, half reported a waiting time of a quarter of a year or less. For this reason, this paper focuses on the factors that predict which caregivers will make an inquiry about a Child Support Grant award, rather than on the receipt of the award.

The Child Support Grant system identifies a child's primary caregiver as the person who has primary responsibility for the child on a daily basis. This person need not be the child's mother. Indeed, the caregiver need not be a woman. However, in the Africa Centre DSA, 87 per cent of Child Support Grant primary caregivers are mothers, 10 per cent are grandmothers, and in 1 per cent of cases the caregiver is an aunt of the child. Fathers are designated as primary caregivers in only 0.2 per cent of cases. With time, we would expect the patterns of grant holding to come to reflect the diverse forms of care giving observed in South Africa, a diversity which preceded the AIDS epidemic but which is no doubt is being reinforced by it.

The Africa Centre data show that children who do not co-reside with their mothers are at risk of not having a child grant. Figure 3 presents the probability of reporting a Child Support Grant, based on the status of children's parents. The first four bars report grants for children whose mothers are resident in the same bounded structure (compound, house) with the child. Fathers are either resident (bar 1), non-resident (bar 2), dead (bar 3), or those whose status is unknown (bar 4), i.e. fathers who are neither resident nor non-resident members of the household, nor known to be dead. Forty-one per cent of children with resident mothers are reported in the grant system. This is in

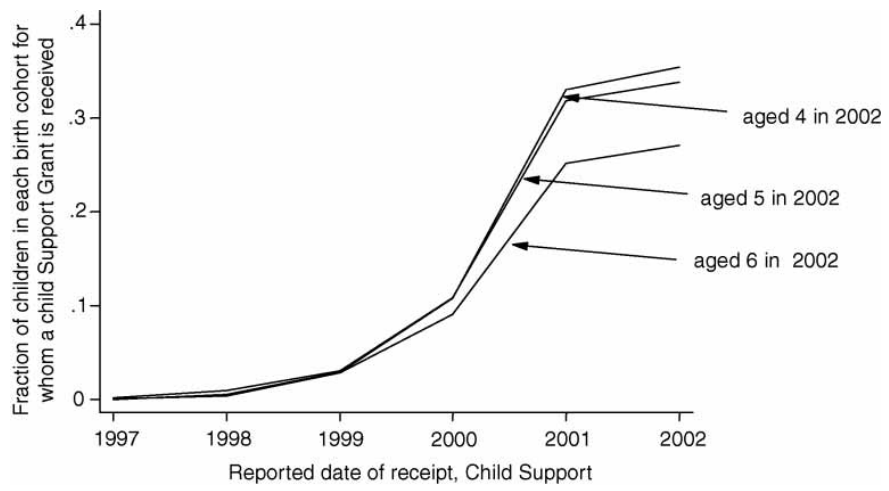

Figure 2: Receipt of a Child Support Grant for children aged 4, 5, or 6 in 2002 


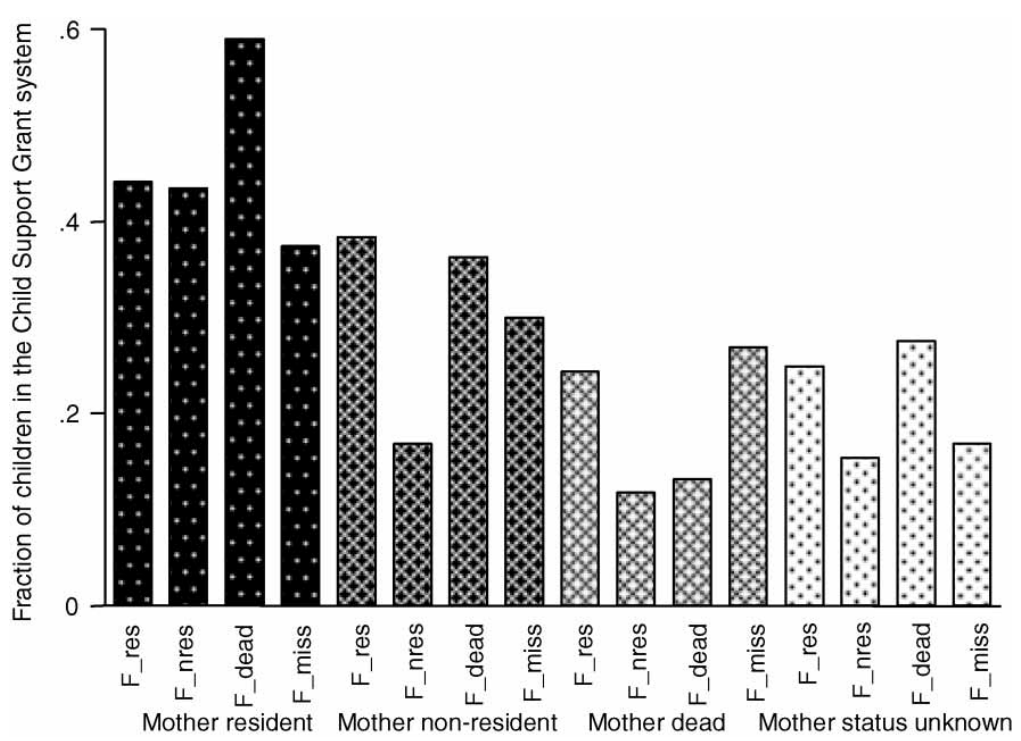

Figure 3: The probability of reporting a Child Support Grant, presented by the status of a child's mother and father. Notes: Reported are the probabilities of reporting a Child Support Grant, based on the vital status of a child's parents. The first four bars report grants for children whose mothers are resident in the same bounded structure with the child. Fathers are either resident (bar 1), nonresident (bar 2), dead (bar 3), or vital status unknown (bar 4)

contrast to 29 per cent of children with non-resident mothers; 23 per cent with mothers who are dead; and 19 per cent with mothers with status unknown. Holding constant father's status, children with resident mothers were significantly more likely to be in the system in 11 of 12 comparisons with children whose mothers were not resident. The exception occurs for the case where mother and father are both resident, relative to that in which the mother is non-resident and the father is resident. In that case, children with mother resident were more likely to be reported with a Child Support Grant (44 per cent versus 38 per cent), but the difference is not significant at the 1 per cent level.

This finding is important for several reasons. First, it is inconsistent with the popular belief that mothers apply for the grant and then leave their children in someone else's care. In addition, it is consistent with other evidence that children living apart from their mothers face special risks. Household expenditure in South Africa on childrelated goods - in particular, on healthy foods - is lower when a child's birth mother is absent (Case et al., 2000). Both in South Africa as a whole and in the DSA, a mother's death is predictive of children not being enrolled in school, and of falling behind the average grade for age (Case \& Ardington, 2004b).

Primary caregivers may not believe themselves to be eligible for a grant if they are not the biological mother of an age-eligible child. While we cannot examine this directly in the data collected by the Africa Centre, we can take an indirect look by analysing whether there are differences between maternal and non-maternal grant holders in their reports of how they first heard about the grant. If non-maternal grant holders are more likely to report having heard about the programme from a source that emphasised their eligibility (government radio spots or welfare offices, 
for example), we might assume that they had better information than the population as a whole. However, we find little difference between maternal and non-maternal grant holder reports about how they heard about the grant, with 54 per cent of maternal and 50 per cent of non-maternal grant holders having heard from family and friends, and 36 per cent of both having heard from a government-sponsored public information announcement on the radio.

In summary, we find that children in this area of rural KwaZulu-Natal are reported to be participating in the Child Support Grant system in large numbers. Half of all respondents who made contact with the grant system recall receiving a grant within three months of having made a first visit to the grant office. This is consistent with our finding that over 80 per cent of children above the age of 1 who had had an inquiry made on their behalf are receiving a grant. The fraction of children at each age in the child grant system appears to plateau at about 40 per cent after 2001. If this continues, it will be cause for concern: in an area as poor as Umkhanyakude, we would expect that the majority of children would be eligible for a Child Support Grant. Additional qualitative research is therefore warranted, to understand the extent to which it is the mothers' absence, or lack of birth certificates, lack of knowledge, or a feeling that others might be more in need, that stops caregivers from applying for Child Support Grants.

\section{TARGETING}

The means tested grant was designed to go to children in poorer households. Two questions about targeting arise. Are poorer people prevented from applying because of the costs associated with doing so? Alternatively, given that nearly all who apply for the grant ultimately receive it, might officials be disbursing the grant without screening for means? Our data shed some light on these questions. At the time of the survey, information was not available on parents' incomes, which limits our ability to examine how closely the means test was followed. However, we can use information available on asset ownership, parents' educations and their employment status to evaluate whether Child Support Grants are reaching poorer households.

In 2001, the Africa Centre collected information on household ownership of both necessities (such as a primus cooker, household furnishings, farm tools) and luxuries (such as televisions, VCRs, cars). Table 1 presents averages of the simple sum of assets owned, for children with and without a Child Support Grant. On average, children with a grant live in households that own significantly fewer assets.

Table 2 presents the results from a probit regression in which reports on Child Support Grants are regressed on a set of indicator variables for luxuries owned. These include a refrigerator, a hot water heater (geyser), a washing machine, a television, a VCR, a computer, and a car. Controlling for a child's age, sex, household size and composition, and parents' status, we find that several luxuries are negatively and significantly associated with reporting a Child Support Grant. The presence of a geyser is associated with a 20 percentage point lower probability of reporting a grant, while a VCR or computer is each associated with a 15 percentage point lower probability. These effects are large, considering that 36 per cent of children below age 7 are reported with a grant. Owning a car is also negatively and significantly associated with reporting a child grant. Indicators for this set of luxury durable goods are highly jointly significant (chi-square test $=80.6$, p-value $=0.0000$ ). 
Table 2: Household assets and the probability of reporting a Child Support Grant. ${ }^{a}$ Dependent variable: $=1$ if informant reports contact with the Child Support Grant system on behalf of this child

\begin{tabular}{lc} 
Explanatory variables: [sample means in brackets] & \\
\hline Indicator: household owns a refrigerator [.455] & .007 \\
Indicator: household owns a hot water heater (geyser) [.014] & $(.014)$ \\
& $-.202^{* *}$ \\
Indicator: household owns a washing machine [.004] & $(.042)$ \\
Indicator: household owns a television [.362] & -.091 \\
& $(.089)$ \\
Indicator: household owns a VCR [.063] & -.005 \\
Indicator: household owns a computer [.005] & $(.014)$ \\
Indicator: household owns a car [.125] & $-.150^{* *}$ \\
& $(.022)$ \\
Chi-square test for the joint significance of these assets (p-value) & -.141 \\
& $(.078)$ \\
Number of observations & $-.039^{* *}$ \\
\hline
\end{tabular}

\footnotetext{
${ }^{a}$ Probit estimates. The numbers reported are changes in the probability of reporting a grant, given a change from 0 to 1 in the right side variable presented. Robust standard errors for these changes are reported in parentheses, where correlation is allowed between unobservables for children in the same household. The statistical significance of underlying probit coefficients are marked: ${ }^{* *}$ significant at a

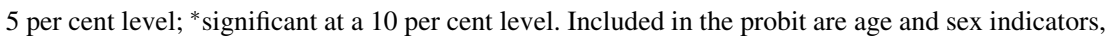
household size and number of non-resident members, and a complete set of indicator variables for parent's status. Sample is restricted to children resident in the DSA on 1 January 2002.
}

In Table 3, we look more closely at whether parents' characteristics predict the report of a Child Support Grant. The first column of Table 3 presents results based on mothers' characteristics, controlling for a complete set of child age indicators, child's sex, household size and composition, the number of assets owned, and a complete set of indicators for mother's age and for father's vital status. The sample is restricted to children for whom it is known that the mother was alive on 1 January 2002, the reference date for the analytical data sets used in this study. We find that the mother's education and employment status are significantly associated with child grant reports. Relative to children whose mothers have completed at least standard 10/grade 12 (the reference category), children whose mothers have less education are 6 to 10 percentage points more likely to report a grant. Children whose mothers are not employed are 14 percentage points (almost 40 per cent) more likely to report a grant than are those whose mothers are reported to be working full-time (the reference category). Many mothers working full-time may earn too much to be eligible for the Child Support Grant.

Our results in Section 2 showed that mothers are overwhelmingly the child's primary caregiver with respect to the Child Support Grant. The results in Table 3 suggest that it is the poorer, less well educated mothers who are more likely to report a grant on 
Table 3: Parental characteristics and the probability of a Child Support Grant. Dependent variable: $=1$ if informant reports contact with the Child Support Grant system on behalf of this child

\begin{tabular}{lcc}
\hline Explanatory variables & Mothers & Fathers \\
\hline Indicator: parent is separated, divorced or widowed & .049 & $-.225^{* *}$ \\
Indicator: parent is not married & $(.040)$ & $(.060)$ \\
Indicator: parent's completed schooling is less than standard 6/grade 8 & $-.049^{* *}$ & $-.057^{* *}$ \\
Indicator: parent's completed schooling is between standard 7 and 9 & $(.019)$ & $.023)$ \\
$\quad$ grade 9 and 11) & $.057^{* *}$ & $.136^{* *}$ \\
Indicator: parent is employed part-time & $.018)$ & $(.028)$ \\
Indicator: parent is not employed & $.098^{* *}$ & $.124^{* *}$ \\
Indicator: other parent is a non-resident household member & $(.018)$ & $(.032)$ \\
Indicator: other parent is dead & .056 & .061 \\
Indicator: other parent is neither a resident nor non-resident household & $(.036)$ & $(.047)$ \\
member, nor is he known to be dead & $.135^{* *}$ & $.125^{* *}$ \\
Number of observations & $(.014)$ & $(.021)$ \\
\hline
\end{tabular}

${ }^{a}$ Probit estimates. Reported are changes in the probability of reporting a grant, given a change from 0 to 1 in the right side variable presented. Robust standard errors for these changes are reported in parentheses, where correlation is allowed between unobservables for children in the same household. The statistical significance of the underlying probit coefficients are marked: ${ }^{* *}$ significant at a 5 per cent level; * significant at a 10 per cent level. The reference category for parent's education is completion of standard 10 (grade 12) or higher. The reference category for parent's employment is 'employed full-time'. The reference category in columns 2 and 3 for other parent's status is 'resident in household'. Sample in column 1 is restricted to children resident in the DSA on 1 January 2002 whose mothers are known to have been alive on 1 January 2002, and in column 2 to children resident in the DSA on 1 January 2002 whose fathers are known to have been alive on 1 January 2002. Included in the probit are age and sex indicators, household size and number of non-resident members, a complete set of indicator variables for parent's age and a complete set of indicator variables for parent's status. Included in father's regression is an indicator that he is polygamous (coefficient insignificant). Where mother's marital status, or education or employment status, is unknown, it is assigned as the mean marital status, education, or employment status for all mothers, and variables are included indicating that mother's marital status, education, or employment status has been assigned.

behalf of a child. Children with unmarried mothers are 5 percentage points less likely to report a grant than are children of married women. It will require further investigation to understand this result. It is unlikely that it is driven by mother's age, education, employment status or the status of the child's father, as all of these are controlled for in Table 3.

The second column in Table 3 shows the relationship between father's characteristics and Child Support Grants. Our sample for column 2 is restricted to children whose fathers were known to be alive on 1 January 2002. Here we again control for a complete set of 
child age indicators, child's sex, household size and composition, and the number of assets owned. In addition, we include a complete set of indicator variables for father's age, including an indicator variable that father's age is not known. As was true of mothers, children with less well educated fathers are significantly more likely to be reported in the Child Support Grant system. Relative to children whose fathers have at least a standard 10/grade 12 education (the reference category), children whose fathers have less than a standard $7 /$ grade 9 education have roughly a 15 percentage point higher probability of a grant, all else being equal. Children with fathers who are not employed are also significantly more likely to be reported in the child grant system. This provides more evidence that the Child Support Grant is reaching poorer children in the community. We ran alternative specifications for Table 3, in which we included information on the number of children aged 0 to 6 , and the number aged 7 to 17 , in the household, and interactions between parents' residency status and their employment status. All the results in Table 3 are robust to the inclusion of these variables.

While mothers' and fathers' socio-economic characteristics have similar effects on Child Support Grants, there are important differences in the effects of parents' status. When a child's mother is not resident in the household (the reference category in column 2 of Table 3), children are significantly less likely to be reported with a grant.

The results presented in Tables 2 and 3 provide evidence that the grant is targeting children in poorer households. However, not all of the poorest children are being reached by the grant. We find that only half of the poorest 2 per cent of children - defined as those living in households with two or fewer assets, whose mothers have six or fewer years of schooling, and whose mothers are not employed - are receiving a Child Support Grant. It will be important to find what can be done to increase take-up for these children.

Quantifying the reach of the Child Support Grant is an important first step in evaluating the programme. In the next section, we turn to the equally important step of quantifying the impact of the programme for poor children in the Umkhanyakude district.

\section{EVALUATING THE PROGRAMME'S IMPACT}

The South African Child Support Grant was introduced without randomised control trials or baseline surveys on children's outcomes of interest - anthropometrics or schoolreadiness, for example. This makes it a challenge to evaluate the programme. That said, there is considerable interest in whether the grant affects children's outcomes, including the quality of care provided to children, their nutritional status, and their school attendance and performance.

We can measure the association between Child Support Grant receipt in 2002 and school enrolment in 2003 and 2004 for children young enough to have received the grant in 2002 and old enough to potentially be enrolled in school when surveyed in 2003 and 2004, using data collected by the Africa Centre. The results of the association between enrolment and grant receipt are presented in Table 4. Primary school enrolment rates in South Africa are high in general, and this is reflected in the DSA, where fully 97 per cent of children aged 8 and 9 are enrolled. However, only 85 per cent of 6 year olds and 95 per cent of 7 year olds are enrolled, suggesting that there is scope for improvement in school enrolment at young ages.

To analyse the relationship between grant receipt and school enrolment, we ran probit regressions of enrolment in 2003/04 on an indicator that the child was reported in 
Table 4: Child Support Grant receipt and school enrolment ${ }^{\mathrm{a}}$

Impact of Child Support Grant receipt on the probability of enrolment, estimated from a probit regression run separately for children of each age

\begin{tabular}{llc}
\hline Age [mean & & Number of \\
enrolment] & Coefficient & observations
\end{tabular}

Impact of future Child Support Grant receipt by a younger sibling on the enrolment of children in year 2000, estim ated from a probit regression run separately for children of each age

\begin{tabular}{llc}
\hline $\begin{array}{l}\text { Age [mean } \\
\text { enrolment] }\end{array}$ & Coefficient & $\begin{array}{c}\text { Number of } \\
\text { observations }\end{array}$
\end{tabular}
School Enrolment 2003/04

\begin{tabular}{lcclcc} 
Age 6 & $.081^{* *}$ & 987 & Age 6 & -.003 & 1060 \\
{$[0.845]$} & $(0.023)$ & & {$[0.951]$} & $(.014)$ & \\
Age 7 & $.018^{* *}$ & 1442 & Age 7 & $-.027^{* *}$ & 1223 \\
{$[0.954]$} & $(.009)$ & & {$[0.953]$} & $(.015)$ & \\
Age 8 & .006 & 1434 & Age 8 & $-.021^{*}$ & 1191 \\
{$[0.976]$} & $(.007)$ & & {$[0.954]$} & $(.014)$ & \\
Age 9 & -.015 & 1396 & Age 9 & -.015 & 1293 \\
{$[0.979]$} & $(.019)$ & & {$[0.956]$} & $(.013)$ & \\
\hline
\end{tabular}

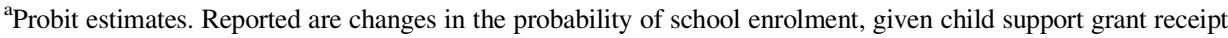
(left-hand panel) or given future grant receipt to a sibling (right-hand panel). Robust standard errors for these changes are reported in parentheses, where correlation is allowed between the unobservables for children who are members of the same household. The statistical significance of the underlying probit coefficients are marked: ** significant at a 5 per cent level; * significant at a 10 per cent level. Included in all regressions are an indicator of the child's sex, mother's completed education, and mother's age on 1 January 2002. When mother's education or age is missing, the relevant variable is assigned a value of zero, and indicator variables are included that her education or age is missing. For the school enrolment probits in the left-hand panel, socio-economic status variables for 2003-04 (measured at the time school enrolment information was collected) are included. These are indicator variables that the child's household has piped water, access to toilet facilities, connection to the electricity grid, and a variable measuring the number of assets the household owned at the time of the 2003-04 survey. In addition, indicators for mother's and father's status at the time of the 2003-04 survey are included. These are indicators signifying that mother is resident in the same bounded structure as the child; mother is dead; mother's status is unknown; father is resident; father is dead; and father's status is unknown. For the school enrolment probits in the right-hand panel, analogous socio-economic and parental status variables for 2001 are included. These were measured in the first half of 2001 at the time information on children's 2000 enrolment information was collected.

2002 to be receiving a grant. The left-hand panel of Table 4 presents the estimated increase in the probability of school enrolment for children receiving the Child Support Grant, estimated from regressions run separately by age for children aged 6 to 9 . Socio-economic status variables are included in each regression. These were measured at the time school enrolment information was collected in the 2003/04 survey. These are indicator variables that the child's household has piped water, access to toilet facilities, connection to the electricity grid, and a variable measuring the number of assets the household owned at the time of the 2003/04 survey. In addition, indicator variables are included for mother's and father's status at the time of the 2003/04 survey. These are indicators signifying that mother is resident in the same bounded structure as the child, mother is dead, mother's status is unknown, father is resident, father is dead, and father's status is unknown. It is particularly important to control for parents' residency status here, given that grant receipt is correlated with mother's presence, and mother's presence independently affects school enrolment. 
We find that Child Support Grant receipt in 2002 is associated with an 8.1 percentage point increase in school enrolment among 6 year olds, and a 1.8 percentage point increase among 7 year olds. For both 6 and 7 year olds, the association between grant receipt and school enrolment is significant. As documented above, households in which grants are received are poorer on average, measured using household assets, parents' educational attainment and employment. That makes the higher enrolment rates among grant recipients all the more remarkable.

There are many possible explanations for higher enrolment among children with grants. The Child Support Grant may improve children's health and nutrition, contributing to their school-readiness. Receipt of a Child Support Grant may free up resources to pay school fees and buy uniforms. However, without additional information, we cannot rule out alternative explanations in which the grant plays no direct role in school enrolment. Primary caregivers who have the energy to apply for a Child Support Grant may be more likely to send their children to school at earlier ages, for example. In such cases, grant receipt may be significantly associated with school enrolment because it is a marker that the child's mother is 'efficient'. We would not want to attribute school enrolment to grant receipt for such children.

We can test this 'efficient mother' hypothesis indirectly using enrolment data on the older siblings of children studied here. Older children in the field site would not have been eligible for Child Support Grants, because the grants were not yet available when these (now older) children were themselves aged 6 or younger. Older siblings thus offer us a 'control group', whose outcomes tell us what we might have expected to see for younger siblings, if the Child Support Grant had not been introduced. Our longitudinal data allow us to look back to the time when older siblings were themselves reaching school age. If grant receipt were merely signalling that a mother was competent, we would expect that the indicator of future grant receipt by a younger sibling would be positively and significantly correlated with older siblings' school enrolment in 2000.

In 2001, households in the DSA were asked whether each child of school age in the household attended school at any point from January 2000 to January 2001. Of all children reported receiving a Child Support Grant (reported in 2002), 37 per cent had at least one maternal sibling who would have been 6 to 9 years old in 2000, and it is to the school enrolment of these children that we now turn our attention.

For the school enrolment probits in the right-hand panel of Table 4, socio-economic and parental status variables measured in 2001 are included. These variables are exact analogues of those included in the left-hand panel (discussed above), but were measured in the first half of 2001, at the time that information on children's 2000 enrolment information was collected. They include mother's education and age in 2001, parents' status (resident, missing, dead) in 2001, and indicators that the child's bounded structure was on the electricity grid and had access to piped water and toilet facilities, and also the number of assets the household owned in 2001. We find no significant association for 6 year olds between school enrolment in year 2000 and an indicator that a maternal sibling would later receive a Child Support Grant. Indeed, for 7 and 8 year olds, the indicator of future grant receipt by a sibling is negatively and significantly related to school enrolment. Children whose siblings will receive the grant in the future hail from the poorer households in the DSA, and the negative correlation may be a reflection of that fact. These results lend no support to the hypothesis that grant receipt is simply acting as a signal that the child's mother is a high achiever. 
Just over 1 per cent of all children reported having received Child Support Grants were themselves 6 to 9 years old in 2000 (58 children), with the majority of these ( 49 children) being aged 6 in 2000. Table 4 currently removes sibships within which a 6 to 9 year old in year 2000 was reported to have received a grant (this removes 84 children from our analysis). The results we present in Table 4 are unchanged if we include these cases.

The relationship between school enrolment and Child Support Grant receipt warrants further study, as does the relationship between grant receipt and children's health and well-being.

\section{CONCLUSIONS}

The reach and impact of other aspects of South African state social assistance - in particular, the success of the state old age pension - have been well documented (Case $\&$ Deaton, 1998; Lund, 2002b). With the ACDIS (Africa Centre Demographic Information System) child grant data we are able to document its reach in rural KwaZulu-Natal, and to offer suggestive findings about its impact. We find that 36 per cent of all children under the age of 7 have had some contact with the Child Support Grant system, with no difference in contact for girls and boys. Between 80 and 90 per cent of children aged 1 to 6 who have had contact with the system were receiving a grant in 2002 . That, in the fifth year of the grant, it was reaching fully a third of age-eligible children in this remote rural area, half of whom received a grant within 3 months, shows a real commitment to implementation.

Is the grant well targeted for poverty? In the absence of income data, we have relied on other measures - parents' education and employment and household asset ownership to assess the programme's success. Children for whom the grant is being obtained have parents who are less well educated, and parents who are less likely to be employed. They live in households that own fewer assets generally, and fewer luxury items in particular. It is likely that the modest size of the cash transfer is leading to a form of self-selection, where better-off primary caregivers are not bothering to go through the application process. Children whose fathers have died are significantly more likely to be receiving a grant. Households with greater numbers of children age-eligible to receive the grant report receiving a larger number of grants, on average. However, among the District's poorest children, only 50 per cent are receiving the grant. More work is necessary to identify the barriers to grant receipt among the poorest households.

Signs of effective targeting are also tempered by the fact that the probability that a child receives a grant depends to a large extent on the presence of a child's mother. Although a child who has lost a father is significantly more likely to receive a grant, this is not true for children who have lost a mother. In fact, holding constant the child's father's status, children whose mothers are non-resident, or dead, or whose status is unknown, are significantly less likely to receive a grant. Lack of widespread knowledge of the fact that primary caregivers need not be mothers provides a possible explanation for our finding. Furthermore, when a mother is absent, the child's primary caregiver may be less able to access the relevant documents necessary for registering the child's birth. The Child Support Grant is currently being extended to children aged 7 to 14, who are even less likely than younger children to be residing with their mothers. In addition, with the AIDS crisis in South Africa, a growing number of children are at risk of their mothers dying. This makes a better understanding of why children with absent mothers are overlooked for the grant essential. 
Does the grant affect children's well-being? Without the benefit of randomised control trials to measure the impact of the Child Support Grant, we turn to longitudinal data from the Africa Centre, in which we can compare school enrolment among maternal siblings. We find a positive and significant association between grant receipt and school enrolment among 6 and 7 year olds young enough to have been eligible for the grant. This is noteworthy, given that on average grant-receiving children have less well-educated parents and are residing in poorer households.

\section{REFERENCES}

ARDINGTON, E, \& LUND, F, 1995. Pensions and development: social security as complementary to programmes of reconstruction and development. Development Southern Africa, 12(4): 557-77.

CASE, A, \& ARDINGTON, C, 2004a. Socio-economic factors. Demographic and health events, Monograph Series, Africa Centre for Health and Population Studies.

CASE, A, \& ARDINGTON, C, 2004b. The impact of parental death on school enrollment and achievement: longitudinal evidence from South Africa. http://www.wws. princeton.edu/ accase/papers.html. Accessed 17 August 2005.

CASE, A, \& DEATON, A, 1998. Large cash transfers to the elderly in South Africa. Economic Journal, 108(450): 1330-61.

CASE, A, LIN, IF, \& MCLANAHAN, S, 2000. How hungry is the selfish gene? Economic Journal, 110(466): 781-804.

DEVEREUX, S, 2001. Social pensions in Namibia and South Africa. IDS Discussion Paper 379. http://www.ids.ac.uk/ids/pvty/pvpub2001.html. Accessed 17 August 2005 GERTLER, PJ, \& BOYCE, S, 2001. An experiment in incentive-based welfare: the impact of PROGRESA on health in Mexico. http://www.iadb.org/res/publications. Accessed 17 August 2005.

HOSEGOOD, V, VANNESTE, A-M, \& TIMÆUS, IM, 2004. Levels and causes of adult mortality in rural South Africa. AIDS, 18: 1-19.

HOSEGOOD, V., \& TIMÆUS, IM, 2001. Household composition and dynamics in KwaZulu Natal, South Africa: mirroring social reality in longitudinal data collection. Paper presented at the African Census Analysis Project Virtual Conference on African Households: an Exploration of Census Data, 21-4 November.

LUND, F, 2002a. Consensus and contestation: the policy for child support in South Africa. Draft Monograph, School of Development Studies, University of Natal.

LUND, F, 2002b. Crowding in care, security and macro-enterprise formation: revisiting the role of the state in poverty reduction, and in development. Journal of International Development, 14(6): 681-94.

SOUTH AFRICAN GOVERNMENT, 1996. Education in South Africa: selected findings from Census '96. http://www.polity.org.za/html/govdocs/reports/education/ educstats.html. Accessed 17 August 2005.

STATISTICS SOUTH AFRICA, 2001. Census 2001. Census in brief. Pretoria: Statistics South Africa. http://www.statssa.gov.za. Accessed 19 July 2005.

\section{APPENDIX: SAMPLE SELECTION}

The number of households we report as answering the grant questionnaire (11 178) excludes one observation for a household that no longer existed at the time of the survey.

In 6075 cases, informants answered affirmatively one or both of the following questions: 'Since 1998, has any adult member of this household received, is in the process of 
applying for, or been refused a grant for a child?' and 'Since 1998, is there any child member of this household for whom an adult who is not a member of this household has applied for, received, or been refused a grant?' For households that answered either question affirmatively, details were to be collected on the adult grant holder, the child, and the type of grant. Information was reported for 6039 of these 6075 cases, in response to the questions 'Is the adult [primary caregiver] registered in the DSA?' 'Is the child registered in the DSA?' and 'What type of grant was received?' Of these 6039 grants, child identifiers were recorded for 5940 cases. (Without child identifiers, we cannot match the grant to a child and, for this reason, those children without child identifiers are not analysed here.) Of the 5940 children with identifiers, the child identifier reported in the grants module did not match that of any individual registered in the DSA data base on 1 January 2002 for 117 grants, reported for 115 individuals. These are also removed from our analysis. Of the 5823 cases remaining, 396 grants were reported for 387 individuals who were not resident in the DSA on 1 January 2002. (We provide information on these children below.) Of the 5427 cases remaining, multiple households reported grants for 157 children (150 children appear twice, 7 children appear three times). For this analysis, we assigned children appearing multiple times to exactly one household, using the following assignment rule. If the child had multiple memberships at the time of the survey, we assigned the child to the bounded structure in which he or she was resident. For those children for whom this did not provide a unique observation, we assigned children to households based on a match between the household assigned to this child in the household memberships file with that recorded in the grant questionnaire. (Details about this procedure are available from the authors.) Of the 5263 children resident in the DSA at the time of the survey for whom a grant is reported, we focus on the 4684 children below the age of 7 for whom a Child Support Grant is reported.

\section{NON-RESIDENT CHILDREN}

Children non-resident in the DSA are not analysed here, because we have no information about the households in which they were living at the time of the survey. These children look similar to resident children for whom grants are reported, along some dimensions, including the distribution of their ages, their mother's and father's educations, mother's employment status, and the probability that their fathers are dead. For these children, mothers are significantly less likely to be the grant holder (5.1 percentage points less likely than is true of resident children for whom a grant is reported), and grandmothers and aunts are significantly more likely to be reported as the grant holder (3.4 and 1.7 percentage points respectively). Non-resident children are 8.2 percentage points less likely to have siblings below the age of 10 who are household members.

\section{GRANT HOLDER CHARACTERISTICS}

Grant holders are not identified for 184 of the 4684 children under the age of 7 reported with a Child Support Grant. A total of 3320 individuals are identified as holding the 4500 grants for which a grant holder is named. Grant holders may be members of one or multiple households. We find 3187 grant holders reported as members of one household; 99 as members of two; and 2 as members of three households. 32 grant holders are not reported as members of any household in the DSA in January 2002, and thus information about their relationship to the household head is not recorded. 